\section{Anti Etanercept and anti SB4 antibodies detection: impact of the assay method}

We would like to underline the fundamental role of the assay method used to detect anti-drug antibodies. In Emery et al's article $^{1}$ a very high percentage of patients show anti-etanercept (ETN) antibodies, 13.1\%, which is much higher compared with main literature data, reporting generally less than 5\% incidence. ${ }^{2-5}$ This apparent discrepancy can be explained by the different technical findings of laboratory methods employed in the works. Emery et al employs electrochemiluminescence method (ECL), while most of the authors performed assays on ELISA or Radio Immuno Assay (RIA) platforms. The diagnostic performances of these methods are very dissimilar.

ECL is known to have characteristics of excellent sensitivity, high drug tolerance, and minimal influence of sample matrix. ${ }^{6}$ Furthermore, Emery et al's work serum samples were subjected to acid treatment before the analysis to increase the anti-drug antibodies recovery.

RIA and ELISA methods have a lower sensitivity and are subjected to drug interference, even though an acid pretreatment of sample can be performed. However, they are much more widely employed worldwide, since they are more standardised and user-friendly than ECL. All these findings could justify the substantial difference in anti-ETN antibodies recovery by ECL, when compared with other methods.

Interestingly, in the Emery et al's work, only $0.7 \%$ of patients had anti-SB4 antibodies. Since in the ECL method the tagged drug (ETN or SB4) is directly used in a single-step assay, ${ }^{7}$ the capability of the assay to detect anti-ETN or anti-SB4 could be identical. Nevertheless, because of the great impact of such new results on clinical management, as also underlined by Moots et $a l^{8}{ }^{8}$ it would be very interesting to study in depth the different immunogenicity of these two drugs found in the cited study. In particular, some more details on the confirmatory test results to evaluate the specificity of detected ADAs, would be clarifying. A very recently published report comparing the immunogenicity of ETN and biosimilar HD203, found ADAs in 8/147 patients taking HD203 and in $3 / 147$ patients taking ETN. ${ }^{9}$ So further studies are needed to better understand factors contributing to different immunogenicity of SB4 than ETN, with a bigger number of patients.

\section{Francesca Meacci, ${ }^{1}$ Mariangela Manfredi, ${ }^{1}$ Maria Infantino, ${ }^{1}$ Valentina Grossi, ${ }^{1}$ Maurizio Benucci ${ }^{2}$ \\ ${ }^{1}$ Immunology and Allergology Laboratory, San Giovanni di Dio Hospital, Florence, Italy \\ ${ }^{2}$ Rheumatology Unit, San Giovanni di Dio Hospital, Florence, Italy}

Correspondence to Dr Francesca Meacci, Immunology and Allergology Laboratory, San Giovanni di Dio Hospital, via di Torre Galli 1, Firenze 50143, Italy; francesca. meacci@uslcentro.toscana.it
Competing interests None declared.

Provenance and peer review Not commissioned; internally peer reviewed.

Data sharing statement This is a comment on a recently published work describing immunogenicity of the Etanercept biosimilar SB4.

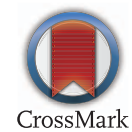

To cite Meacci F, Manfredi M, Infantino M, et al. Ann Rheum Dis 2016;75:e39.

Received 5 April 2016

Accepted 8 April 2016

Published Online First 29 April 2016

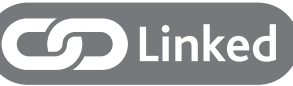

- http://dx.doi.org/10.1136/annrheumdis-2016-209696

Ann Rheum Dis 2016;75:e39. doi:10.1136/annrheumdis-2016-209665

\section{REFERENCES}

1 Emery P, Vencovský J, Sylwestrzak A, et al. A phase III randomised, double-blind, parallel-group study comparing SB4 with etanercept reference product in patients with active rheumatoid arthritis despite methotrexate therapy. Ann Rheum Dis 2015:Published Online First 6 Jul 2015. doi:10.1136/annrheumdis-2015207588

2 Combe B, Codreanu C, Fiocco U, et al. Etanercept European Investigators Network (Etanercept Study 309 Investigators). Etanercept and sulfasalazine, alone and combined, in patients with active rheumatoid arthritis despite receiving sulfasalazine: a double-blind comparison. Ann Rheum Dis 2006; 65:1357-62.

3 Keystone EC, Schiff MH, Kremer JM, et al. Once-weekly administration of $50 \mathrm{mg}$ etanercept in patients with active rheumatoid arthritis: results of a multicenter, randomized, double-blind, placebo-controlled trial. Arthritis Rheum 2004;50: 353-63.

4 Bathon JM, Martin RW, Fleischmann RM, et al. A comparison of etanercept and methotrexate in patients with early rheumatoid arthritis. $N$ Engl J Med 2000;343:1586-93.

5 Jani M, Chinoy H, Warren RB, et al. Biologics in Rheumatoid Arthritis Genetics and Genomics Study Syndicate Collaborators. Clinical utility of random anti-tumor necrosis factor drug-level testing and measurement of antidrug antibodies on the long-term treatment response in rheumatoid arthritis. Arthritis Rheumatol 2015;67:2011-19.

6 Nencini F, Pratesi S, Petroni G, et al. Assays and strategies for immunogenicity assessment of biological agents. Drug Dev Res 2014;75(Suppl 1):S4-6.

7 Mikulskis A, Yeung D, Subramanyam M, et al. Solution ELISA as a platform of choice for development of robust, drug tolerant immunogenicity assays in support of drug development. J Immunol Methods 2011;365:38-49.

8 Moots RJ, Balsa A, Wolbink G. Reporting of potential immunogenicity with biologic drugs: clarity and accuracy required. Ann Rheum Dis 2016;75:e24.

9 Bae SC, Kim J, Choe JY, et al. HERA Study Investigators. A phase III, multicentre randomised, double-blind, active-controlled, parallel-group trial comparing safety and efficacy of HD203, with innovator etanercept, in combination with methotrexate, in patients with rheumatoid arthritis: the HERA study. Ann Rheum Dis 2016; Published Online First 23 Feb 2016. doi:10.1136/annrheumdis2015-207613 